\title{
COVID-19 Salgını Sonrası Paramedik Öğrencilerinin Mesleğe Bakış Açılarının Belirlenmesi
}

\author{
Determination of Paramedic Students' Perspectives on the Profession after the COVID-19 \\ Outbreak
}

Serap GÜNGÖR ${ }^{1}$ (D), Hakan AVAN ${ }^{1}$ (D), Vedat ARGIN ${ }^{1}$

ÖZ

Amaç: $\mathrm{Bu}$ araştırma, COVID-19 salgını sonrası paramedik öğrencilerinin mesleğe bakış açılarını belirlemek amacıyla yapılmıştır.

Gereç ve Yöntem: Tanımlayıcı tipte kesitsel bir çalışma olarak planlanan araştırma 01-15 Haziran 2020 tarihleri arasında, 397 paramedik öğrencisi ile tamamlanmıştır. Veri toplama formu olarak 30 ifadeden oluşan "Tanıtıcı Anket Formu” kullanılmıştır. Verilerin analizinde tanımlayıcı istatistiksel yöntemler, t-testi, ANOVA analizleri kullanılmıştır.

Bulgular: Bu araştırmaya; yaş ortalaması 20,64 $\pm 2,07$ olan ve çoğunluğu $(\% 64,2)$ kadınlardan oluşan 397 öğrenci katılmıştır. Öğrencilerin; \%53,9'unun salgın haline gelen COVID-19'dan korkmadığı tespit edilmiştir. Araştırmaya katılan bireylerin \%74,6'sının acil sağlık hizmetleri biriminin salgın açısından yüksek riskli olduğu, \%50,1'inin sağlık kurumlarında çalışanlara yönelik alınan önlemlerin yeterli olmadığı, \%69' ünün alınan önlemlerin çalışanların kaygı düzeyini etkilediği, \%47,4'ünün içinde bulunduğumuz salgından dolayı gelecek kaygısı yaşadığı saptanmıştır.

Sonuç: Öğrencilerin salgın süresince paramedik mesleğini yapmak istedikleri, çevresindeki insanlara paramedik mesleğini tavsiye edecekleri sonucuna ulaşılmıştır.

Anahtar Kelimeler: Bakış açısı, COVID-19, meslek, paramedik, öğrenci

\section{ABSTRACT}

Aim: This research was conducted to determine the perspective of paramedic students towards the profession after the outbreak of COVID-19. Materials and Methods: The study, which was planned as a descriptive cross-sectional study, was

Serap GÜNGÖR (四)

Kahramanmaras Sutcu Imam University, Kahramanmaras Health Services Vocational School

e-mail:serap_32_06@hotmail.com completed between 01-15 June 2020 with 397 paramedic students. "Introductory Questionnaire Form" consisting of 30 statements was used as the data collection form. Descriptive statistical methods, t-test, ANOVA analysis were used in the analysis of the data. Results: 397 students, mostly women (64.2\%), with a meanage of $20.64 \pm 2.07$, participated in this study. Of the individuals participating in the study, $74.6 \%$ of the emergency health services unit is at high risk in terms of outbreak, $50.1 \%$ of the measures taken against employees in health institutions are not sufficient, $69 \%$ of the measures taken affect the anxiety level of the employees, $47.4 \%$ ' It has been determined that the reputation is anxious for the future due to the outbreak we are in.

Conclusion: It was concluded that the students wanted to do the paramedic profession during the epidemic and would recommend the paramedic profession to the people around them.

Keywords: COVID-19, job, paramedic, perspective, student

\section{GİRIŞ}

Acil sağlık hizmetleri çalışanları koronavirüsle (COVID-19) mücadele sürecinde hasta ile ilk temas eden ve en çok risk altında bulunan meslek grubudur (1). İlk ve acil yardım teknikeri (paramedik) acil sağlık hizmetleri ekibinin bir parçasını oluşturmaktadır (2). Paramedik mesleği ilk olarak Amerika Birleşik Devletleri'nde sivil alanlardaki ölümlerin azaltılmasında faydalı olacağı düşünülmesi sonucu, yaygınlaşmaya başlayan bir meslek grubudur. Ülkemizde 2004 yılından itibaren profesyonel paramedikler 112 ambulans servislerinde görev almaya başlamışlardır (3). Paramedikler; hastaya acil bakımda muhtemel tanıyı koyabilecek, hastalığın tanı ve tedavisinde hekimin gerekli gördüğü ilaçları uygulayabilecek mesleki bilgi ve beceriye sahip olmalıdır (4). Paramedikler acil / afet durumunda her zaman ön saflarda yer alır ve görevlerini yerine getirmeleri için kendi hayatları dahil her türlü riski göze alırlar.

Dünya Sağlık Örgütü 30 Ocak 2020'de koronavirüs salgınını resmi olarak uluslararası endişe verici bir halk 
sağlığ1 sorunu olarak görmüş ve acil durum ilan etmiştir $(5,6)$. Paramedikler koronavirüs hastalarılla yakın temasta olduğundan, enfeksiyona maruz kalma ihtimalleri daha yüksektir. Paramediklerin virüsü meslektaşları ve aile üyeleri arasında yayma riskleri daha fazladır. Bugüne kadar, dünya genelinde binlerce sağlık personeli COVID-19 ile enfekte olmuş ve onlarcası ölmüştür. COVID-19 salgını küresel sağlık hizmetleri işgücü üzerindeki baskıyı arttırmaktadır. Bu baskının birincisi, sağlık sistemi kapasitesini vurgulayan potansiyel olarak ezici hastalık yükü, ikincisi ise enfeksiyon riski ile birlikte sağlık çalışanları üzerindeki olumsuz etkileridir (7). Bu etkiler aynı zamanda sağlık personelinin ruh sağlığını da olumsuz yönde etkilemektedir $(6,8)$. Sağlık personellerine ihtiyaç duyulan bu dönemde mesleğe yeni katılmak üzere olan, COVID-19 sürecinden dolay1 uygulamalı ve staj derslerini uzaktan eğitimle tamamlayan öğrencilerin mesleğe aidiyet duygusu kazanmaları önemli bir kriterdir.

\section{GEREÇ VE YÖNTEM}

\section{Araştırmanın tasarımı}

$\mathrm{Bu}$ çalışma bir devlet üniversitesinin sağlık hizmetleri meslek yüksekokulunda İlk ve Acil Yardım Programı'nda eğitim gören öğrencilere elektronik ortamda, 01-15 Haziran 2020 tarihleri arasında COVID-19 salgını sonrası mesleğe bakış açılarının belirlenmesi amacıyla tanımlayıcı tipte kesitsel olarak yapılmıştır.

\section{Araştırmanın evreni ve örneklemi}

Araştırmanın evrenini, bir devlet üniversitesi sağlık hizmetleri meslek yüksekokulunda İlk ve Acil Yardım Programı'nda öğrenim gören 422 öğrenci oluşturmuştur. Araştırmada örneklem hesabına gidilmemiş olup, gönüllü olan ve alınma ölçütlerini karşılayan, anket sorularını dolduran 397 öğrenci ile araştırma tamamlanmıştır.

Elektronik ortamda oluşturulan gönüllülük olur formu ve anket sorularının linki öğrencilerle elektronik ortamda paylaşılmıştır. Gönüllülük esasına dayanarak anketleri doldurmaları sağlanmıştır.

\section{Tanitıci Anket Formu}

$\mathrm{Bu}$ form; yaş, cinsiyet, kardeş sayısı vb. sosyodemografik sorular ile araştırmacıların literatür taramaları
(4-11) sonucunda oluşturduğu COVID-19 bilgilerini tanımlayıcı toplam 30 ifadeden oluşmaktadır.

\section{Araștırma sorulart}

- COVID-19 salgını sonrası paramedik öğrencilerinin mesleğe bakış açısı nasıldır?

- COVID-19 salgını sonrası paramedik öğrencilerinin mesleğe bakış açısı çeşitli faktörlere (sosyo-demografik özellikler) göre farklılaşmakta mıdır?

\section{Araştırmanın uygulanması}

Araştırma, 01 - 15 Haziran 2020 tarihleri arasında araştırmacılar tarafindan elektronik ortamda oluşturulan anket soruları linki öğrencilerle paylaşılmış ve gönüllülük esasına dayanarak bireylerin anketleri doldurması sağlanmıştır.

\section{Istatistiksel analiz}

Araştırmanın verileri tamamen gizli tutularak bilgisayar ortamında SPSS 22.0 programında analiz edilmiştir. Verilerin analizinde, sayı, yüzde, ortalama, standart sapma, t-testi, Ki-kare testi, ANOVA testi ile değerlendirilmiştir.

\section{Araştırmanın etik boyutu}

Araştırmaya başlamadan önce Kahramanmaraş Sütçü İmam Üniversitesi Klinik Olmayan Araştırmalar Etik Kurulundan (29.04.2020 tarihli, 2020/08 oturum nolu, karar no:05) ve Sağllk Hizmetleri Meslek Yüksekokulu Müdürlüğü’nden yazılı izin alınmıştır. Öğrencilere link paylaşımı yapılmadan önce araştırmanın amacı, yararları açıklanarak, gönüllülük ilkesi doğrultusunda sözel onamları alınmıştır. Öğrenciler anketleri isim belirtmeksizin tamamlamışlardır. Araştırma, Helsinki Deklarasyonu Prensipleri'ne uygun olarak yapılmıştır.

\section{BULGULAR}

Araştırmamıza; yaş ortalaması $20,64 \pm 2,07$ olan ve çoğunluğu $(\% 64,2)$ kadınlardan oluşan, \%66,8'si sağlık meslek lisesinde ortaöğrenimini tamamlamış 397 birey katılmıştır. Çalışmaya katılan bireylerin \%50,4'ünün şehirde doğduğu, kardeş sayısının 0 ile 13 arasında değiştiği, $\% 53,7$ 'sinin gelirinin giderine eşit olduğu ve \%91,7'sinin 
herhangi bir kronik hastalığı bulunmadığı belirlenmiştir (Tablo 1).

Tablo 1. Öğrencilerin sosyo-demografik özelliklerinin dağılımı

\begin{tabular}{|c|c|c|}
\hline Özellikler & Ort \pm s.s & Min-Max \\
\hline Yaşınız (yıl) & $20,64 \pm 2,07$ & $18-35$ \\
\hline \multirow[t]{2}{*}{ Kardeş Sayısı (kişi) } & $3,19 \pm 1,87$ & $0-13$ \\
\hline & $\mathbf{n}$ & $\%$ \\
\hline \multicolumn{3}{|l|}{ Cinsiyet } \\
\hline Kadın & 255 & 64,2 \\
\hline Erkek & 142 & 35,8 \\
\hline \multicolumn{3}{|l|}{ Doğduğu yer } \\
\hline Köy & 59 & 14,9 \\
\hline Kasaba & 13 & 3,3 \\
\hline İlçe & 125 & 31,5 \\
\hline Şehir & 200 & 50,4 \\
\hline \multicolumn{3}{|l|}{ Gelir durumu } \\
\hline Gelirimiz giderimizden fazla & 128 & 32,2 \\
\hline Gelirimiz giderimizden az & 213 & 53,7 \\
\hline Gelirimiz giderimize eşit & 56 & 14,1 \\
\hline \multicolumn{3}{|c|}{ Mezun olduğu ortaöğretim kurumu } \\
\hline Düz Lise & 5 & 1,2 \\
\hline Teknik ve Mesleki Lise & 29 & 7,3 \\
\hline İmam Hatip Lisesi & 8 & 2,1 \\
\hline Anadolu-Fen Lisesi & 80 & 20,2 \\
\hline Açık Öğretim Lisesi & 10 & 2,4 \\
\hline Sağlık Meslek Lisesi & 265 & 66,8 \\
\hline \multicolumn{3}{|l|}{ Kronik hastalık varlığ } \\
\hline Evet & 33 & 8,3 \\
\hline Hayır & 364 & 91,7 \\
\hline
\end{tabular}

Bireylerin \%86,4'ü olas1 COVID-19 hastasiyla karşılaşmadığı, \%53,9'u da salgın haline gelen COVID19 'dan korkmadığı tespit edilmiştir. Bireylerin \%82,3'ünün COVID-19 salgını süresince paramedik mesleğini yapmak istediği, \%72,5'inin çevresindeki insanlara paramedik mesleğini tavsiye edeceği saptanmıştır (Tablo 2).

Bireylerin \%74,6'sının acil sağlık hizmetleri biriminin salgın açısından yüksek riskli olduğu, \%50,1'inin sağlık kurumlarında çalışanlara yönelik alınan önlemlerin yeterli olmadığı, \%69' ünün alınan önlemlerin çalışanların kayg1 düzeyini etkilediği, \%47,4'ünün içinde bulunduğumuz salgından dolayı gelecek kaygısı yaşadığı, \%39,8'inin de virüs bulaştırmaktan korktuğu belirlenmiştir (Tablo 2).
Tablo 2. Öğrencilerin salgın hakkında duyguları ve paramedik mesleğine yönelik görüşleri

\begin{tabular}{|l|c|c|}
\hline & n & \% \\
\hline Olası COVID-19 hastasıyla karşılaştınız mı? & 54 & 13,6 \\
\hline Evet & 343 & 86,4 \\
\hline Hayır & \multicolumn{1}{|c|}{} \\
\hline COVID-19 salgınından korkuyor musunuz? & 46,1 \\
\hline Evet & 183 & 53,9 \\
\hline Hayır & 214 & \\
\hline
\end{tabular}

COVID-19 salgını süresince paramedik mesleğini yapmak ister misiniz?

\begin{tabular}{|l|c|c|}
\hline Evet & 327 & 82,3 \\
\hline Hayır & 13 & 3,3 \\
\hline Kararsızım & 57 & 14,4 \\
\hline Paramedik mesleğini çevrenizdeki kişilere tavsiye eder misiniz? \\
\hline Evet & 288 & 72,5 \\
\hline Hayır & 37 & 9,3 \\
\hline Kararsızım & 72 & 18,1 \\
\hline
\end{tabular}

Acil sağlık hizmetleri biriminin sizce salgın açısından risk durumu nedir?

\begin{tabular}{|l|c|c|}
\hline Yüksek derece riskli & 296 & 74,6 \\
\hline Orta derece riskli & 84 & 21,2 \\
\hline Düşük derece riskli & 17 & 4,3 \\
\hline
\end{tabular}

\begin{tabular}{|l|c|c|}
\hline $\begin{array}{l}\text { Sağlık kurumlarında çalışanlara } \\
\text { yönelik alınan önlemlerin yeterli } \\
\text { olduğunu düşünüyor musunuz? }\end{array}$ & $\mathrm{n}$ & $\%$ \\
\hline Evet & 198 & 49,9 \\
\hline Hayır & 199 & 50,1 \\
\hline
\end{tabular}

Sağlık kurumlarında çalışanlara yönelik alınan önlemlerin kaygı düzeyinizi etkilediğini düşünüyor musunuz?

\begin{tabular}{|l|c|c|}
\hline Evet & 274 & 69,0 \\
\hline Hayır & 123 & 31,0 \\
\hline
\end{tabular}

Şu anki ruhsal durumunuzla ilgili sizi en çok etkileyen durum/ları belirtiniz.*

\begin{tabular}{|l|c|c|}
\hline Hiç etkilenmedim & 45 & 11,3 \\
\hline Virüs bulaşma korkusu & 128 & 32,2 \\
\hline Virüs bulaştırma korkusu & 158 & 39,8 \\
\hline Ölüm korkusu & 27 & 6,8 \\
\hline Temizlik takıntılarım başladı & 80 & 20,2 \\
\hline Gelecek kaygısı yaşıyorum & 188 & 47,4 \\
\hline Üzüntülü hissediyorum & 137 & 34,5 \\
\hline Koronafobi oldum & 15 & 3,8 \\
\hline
\end{tabular}

*Öğrenciler birden fazla cevap vermişlerdir. Yüzdeler n= 397 üzerinden alınmıştır

Bireylerin salgın sürecinde \%35,8'inin paramedik olarak çalıştığında COVID-19 olma ihtimalinin çok yüksek olduğu, \%46,3'ünün COVID-19 olma ihtimalinin diğer insanlardan daha yüksek olduğu, \%59,7'sinin COVID-19 
taşıyıcısı ise ailesine bulaştırma ihtimalinin çok yüksek olduğu gibi düşünceler içerdiği belirlenmiştir (Tablo 3).

Bireylerin \%12.8' inin COVID-19 hastası olmaktan korkmadığı, \%66,8'inin karantina şartlarına riayet ederse COVID-19 hastası olma riskinin kesinlikle azalacağ1, \%43,8'inin paramedik olarak çalışma ortamında sosyal mesafeyi sağlayabilirse COVID-19 hastası olma riskinin kesinlikle azalacağı düşüncesinde oldukları tespit edilmiştir (Tablo 3).

Bireylerin \%34,8'i hastanın tedavisi surasında yapması gereken mesleki becerilerin engellenmesi konusunda, \%27,7'si hastaya kardiyopulmoner resüsitasyon, entübasyon, bronkoskopi vb. uygulamaları yapma konusunda, \%29,0'1 hasta ile uzun süreli maruziyetin kendisini endişelendireceği konusunda, \%27,5'i de çalışırken kişisel koruyucu ekipmanları tam olsa bile hasta bireye temas etmenin kendisini korkutacağ 1 konusunda kararsız olduğunu ifade etmiştir (Tablo 3).

Tablo 3. Öğrencilerin salgın sürecinde paramedik olarak çalışmaya yönelik düşünceleri

\begin{tabular}{|c|c|c|}
\hline & $\mathbf{N}$ & $\%$ \\
\hline \multicolumn{3}{|c|}{$\begin{array}{l}\text { Paramedik uygulamaları sırasında COVID-19 olma ihtimalim çok } \\
\text { yüksektir. }\end{array}$} \\
\hline Kesinlikle katılmıyorum & 20 & 5,0 \\
\hline Katılmiyorum & 40 & 10,0 \\
\hline Kararsızım & 111 & 28,0 \\
\hline Kat1lyorum & 84 & 21,2 \\
\hline Kesinlikle katılıyorum & 142 & 35,8 \\
\hline \multicolumn{3}{|c|}{$\begin{array}{l}\text { Paramedik olarak COVID-19 olma ihtimalim diğer insanlara göre } \\
\text { daha yüksektir. }\end{array}$} \\
\hline Kesinlikle katılmıyorum & 19 & 4,8 \\
\hline Katılmıyorum & 29 & 7,3 \\
\hline Kararsızım & 61 & 15,4 \\
\hline Kat1liyorum & 104 & 26,2 \\
\hline Kesinlikle katıliyorum & 184 & 46,3 \\
\hline \multicolumn{3}{|c|}{$\begin{array}{l}\text { Paramedik olarak çalıştığımda COVID-19 taşıyıcısı isem aileme } \\
\text { bulaştırma ihtimalim çok yüksektir. }\end{array}$} \\
\hline Kesinlikle katılmıyorum & 14 & 3.5 \\
\hline Katılmiyorum & 17 & 4.3 \\
\hline Kararsızım & 54 & 13.6 \\
\hline Kat1liyorum & 75 & 18.9 \\
\hline Kesinlikle katılıyorum & 237 & 59.7 \\
\hline \multicolumn{3}{|c|}{$\begin{array}{l}\text { Paramedik olarak çalıștığımda COVID-19 taşıyıcısı isem çalışma } \\
\text { arkadaşlarıma bulaștırma ihtimalim çok yüksektir. }\end{array}$} \\
\hline Kesinlikle katılmıyorum & 11 & 2,8 \\
\hline Kat1lmiyorum & 28 & 7,0 \\
\hline Kararsızım & 50 & 12,6 \\
\hline Kat1lyorum & 73 & 18,4 \\
\hline Kesinlikle katıliyorum & 235 & 59,2 \\
\hline
\end{tabular}

\begin{tabular}{|l|c|c|}
\hline Kesinlikle katılmiyorum & 51 & 12,8 \\
\hline Katılmıyorum & 65 & 16,4 \\
\hline Kararsızım & 115 & 29,0 \\
\hline Katıliyorum & 75 & 18,9 \\
\hline Kesinlikle katıliyorum & 91 & 22,9 \\
\hline
\end{tabular}

Karantina şartlarına riayet edersem COVID-19 olma riskim azalır.

\begin{tabular}{|l|c|c|}
\hline Kesinlikle katılmiyorum & 7 & 1,8 \\
\hline Katılmiyorum & 20 & 5,0 \\
\hline Kararsızım & 45 & 11,3 \\
\hline Katıliyorum & 60 & 15,1 \\
\hline Kesinlikle katıliyorum & 265 & 66,8 \\
\hline
\end{tabular}

Paramedik olarak çalışma ortamında sosyal mesafeyi sağlayabilirsem COVID-19 olma riskim azalır.

\begin{tabular}{|l|c|c|}
\hline Kesinlikle katılmiyorum & 16 & 4,0 \\
\hline Katılmiyorum & 35 & 8,9 \\
\hline Kararsızım & 93 & 23,4 \\
\hline Katıliyorum & 79 & 19,9 \\
\hline Kesinlikle katıliyorum & 174 & 43,8 \\
\hline
\end{tabular}

COVID-19'un bulaşıcı riskleri hastaya tedavi ve bakım sırasında yapmam gereken mesleki etkinlikleri yerine getirmemi engeller.

\begin{tabular}{|l|c|c|}
\hline Kesinlikle katılmiyorum & 105 & 26,4 \\
\hline Kat1lmiyorum & 62 & 15,6 \\
\hline Kararsızım & 138 & 34,8 \\
\hline Kat1liyorum & 45 & 11,4 \\
\hline Kesinlikle katıliyorum & 47 & 11,8 \\
\hline
\end{tabular}

Paramedik olarak çalıştığımda COVID-19 işime olan motivasyonumu düşürür.

\begin{tabular}{|l|c|c|}
\hline Kesinlikle katılmiyorum & 115 & 29,0 \\
\hline Katılmiyorum & 72 & 18,2 \\
\hline Kararsizım & 93 & 23,4 \\
\hline Katıliyorum & 70 & 17,6 \\
\hline Kesinlikle katıllyorum & 47 & 11,8 \\
\hline
\end{tabular}

Paramedik olarak çalışığımda hastaya kardiyopulmoner resüsitasyon, entübasyon, bronkoskopi vb. uygulamalar yapmak beni endișelendirir.

\begin{tabular}{|l|c|c|}
\hline Kesinlikle katılmiyorum & 83 & 20,9 \\
\hline Katılmiyorum & 55 & 13,9 \\
\hline Kararsizım & 110 & 27,8 \\
\hline Katıliyorum & 59 & 14,7 \\
\hline Kesinlikle katıliyorum & 90 & 22,7 \\
\hline
\end{tabular}

Paramedik olarak çalıştığımda hasta kişi ile uzun süreli maruziyet beni endişelendirir.

\begin{tabular}{|l|c|c|}
\hline Kesinlikle katılmiyorum & 43 & 10,8 \\
\hline Katılmiyorum & 50 & 12,6 \\
\hline Kararsızım & 117 & 29,5 \\
\hline Katıliyorum & 81 & 20,4 \\
\hline Kesinlikle katıliyorum & 106 & 26,7 \\
\hline
\end{tabular}

Paramedik olarak çalıştığımda kişisel koruyucu ekipmanlar olsa bile hastaya temas etmek beni korkutur.

\begin{tabular}{|l|c|c|}
\hline Kesinlikle katılmiyorum & 68 & 17,1 \\
\hline Katılmiyorum & 75 & 18,9 \\
\hline Kararsızım & 109 & 27,5 \\
\hline Katıliyorum & 67 & 16,9 \\
\hline Kesinlikle katıliyorum & 78 & 19,6 \\
\hline
\end{tabular}




\section{TARTIŞMA}

Dünyada ve ülkemizde COVID-19 salgın nedeniyle oluşan vakalarla sürekli temas halinde bulunan sağlık çalışanları hastalığa yakalanmakta hatta hayatlarını kaybetmektedir. Acil sağlık hizmeti sunan paramediklerin HIV, Hepatit-B, Hepatit-C, Metisiline Dirençli Stafilokok Aureus kolonizasyonu, İnfluenza, Akut Solunum Yolu Sendromu (SARS) ve COVID-19 gibi bulaşıcı hastalıklara karşı halka ve diğer sağ lık çalışanlarına kıyasla daha fazla risk altında olduğu görülmektedir $(9,10)$. Araştırmamıza katılan geleceğin paramediklerinin mesleklerini icra edecekleri görülmektedir. Bunun sebebi bireylerin çoğunluğunun COVID-19 hastası ile karşılaşmaması, vicdani sorumluluk duygusundan ve mesleğini kutsal bir meslek grubu olarak görmesinden kaynaklandığ düşünülmektedir. Paramedik eğitimi gören bireylerle yapılan bir çalışmada; katılımcıların meslekle ilgili genel görüşlerinin mesleğin kutsal ve sabır gerektiren bir meslek gurubu olduğu bildirilmiştir (3). Güney Kore'de hemşirelik öğrencilerine yönelik Ortadoğu Solunum Sendromu (MERS) salgını ile ilgili yapılan çalı̧̧mada öğrencilerin mesleklerine bakış açısının değişmediği, kendilerini koruyucu davranış puanlarının ise orta düzeyde olduğu bildirilmiştir (11).

Araştırmaya katılan bireyler paramedik mesleğini salgın açısından yüksek riskli bulmaktadır. Yüksek risk çalışanların kaygı düzeyini etkilemektedir. Fakat araştırmaya katılan bireylerin çoğunluğu, COVID-19' un mesleksel motivasyonlarını etkilemeyeceğini düşünmektedir. Bireylerin üniversiteye yerleştirme döneminde paramedik mesleğini severek ve isteyerek tercih ettiklerinden dolayı mesleklerinin icrası esnasında salgın gibi olumsuzlukların işlerine olan motivasyonlarını etkilemeyeceği düşünülmektedir. (11). Öğrencilerin müfredatlarında COVID-19 gibi salgın hastalıklara yaklaşımlarına yer verilmesi öğrencilerin mesleğe başladığında salgına yönelik kaygı düzeylerini azaltması beklenmektedir (12).

COVID - 19 özellikle kronik hastaları daha fazla etkilediği ve mortalite ile sonuçlanabildiği için kronik hastalığı bulunan sağlık çalışanlarını daha fazla etkilenmektedir. Yapılan çalışmalarda kronik hastalığ bulunan acil sağlık hizmeti çalışanlarının COVID-19' a karşı hem bilgi düzeyleri hem de tutumları daha yüksek bulunmuştur (9). Acil sağlık hizmeti sunumunda kalite standartlarını düşürmemek için çalışanların kaygılarını azaltacak önlemleri almaları, kronik hastalığı bulunan personelin salgın sürecinde COVID-19 ile karşılaşma olasılığı daha az olan birimlerde görevlendirilmeleri gerektiği düşünülmektedir.

Araştırmaya katılan bireylerin çoğunluğu, paramedik olarak çalıştığında COVID-19 tanısı pozitif olan hastaların tedavisinde yapması gereken tüm mesleki etkinlikleri yerine getireceğini düşünmektedir. COVID-19 salgını sırasında diş hekimlerine yönelik yapılan çalışmada araştırmamıza benzer sonuç bulunmuştur (13). Tüm sağlık çalışanlarında olduğu gibi paramedik mesleğini yapacak olan bireylerinde hem vicdani açıdan hem de mesleğin getirmiş olduğu etik sorumluluk duygusundan dolayı tüm şartlarda hasta sağlığı için yapılması gereken uygulamaları eksiksiz yerine getirecekleri görülmektedir.

Araştırmaya katılan bireyler kişisel koruyucu ekipmanları olsa bile hastayla uzun süre aynı ortamda bulunmakta ve hasta bireye temas etmekte karasiz kalmıştır. Bireylerin kararsız kalmasının sebebi; COVID19'un yeni ortaya çıkan bir hastalık türü olması, hastalığın özelliklerinin, hastalığın tedavisinin tam olarak bilinmemesi nedeniyle olduğu düşünülmektedir.

Araştırmaya katılan bireylerin karantina şartlarına riayet ettiğinde ve sosyal mesafe kurallarına uyduğunda COVID-19' a yakalanma risklerinin azalacağını belirtmişlerdir. COVID-19' un bulaşıcı, salgın bir hastalık olduğundan bireylerin hastalığa yakalanmamak için hastalık etkenini taşıyan kişilerden uzak durmanın hastalığa yakalanma riskini azaltacağını düşünmüş olabilirler.

Araştırmaya katılan bireylerin çoğunluğu, COVID-19 salgını sürecinde kardiyopulmoner resüsitasyon, entübasyon, bronkoskopi vb. uygulamalar yapmanın veya uygulamalar sırasında aynı ortamda bulunmanın kendilerini endişelendirmeyeceğini düşünmektedir. Bununla birlikte COVID-19 salgınında sağlı çalışanlarında riskin azaltılmasına yönelik yapılan çalışmada, kardiyopulmoner resüsitasyon, entübasyon, bronkoskopi, nebulizatör tedavisi ve sekresyon aspirasyonu gibi uygulamalarda bulunan sağlık çalışanlarının yüksek riske maruz kalmasına neden olduğu bildirilmiştir (14). Paramediklerin çok sık yaptıkları bu uygulamalar paramediklerin de salgında yüksek riske maruz kalmasına sebep olabilmektedir.

$\mathrm{Bu}$ çalışmaya katılan bireyler sağlık kurumlarında salgın sürecinde çalışanlara yönelik alınan önlemlerin, çalışanların kaygı düzeyini etkilediği ve bireylerin salgın sürecinde paramedik olarak çalışmaya yönelik düşüncelerinin; koronavirüsü ailesine ve çalışma arkadaşlarına bulaştırma riskinin çok yüksek olduğunu düşünmektedir. COVID-19 
salgını ile ruh beden ilişkisi incelemek üzere yapılan çalışmada, COVID-19 olma ihtimaline karşın alınan; sosyal izolasyon, yakınlarından ayrı kalma, çalışma usullerinde meydana gelen değişiklikler gibi birçok aktivite nedeniyle kaygı ve kaygı ile bağlantılı birçok ruhsal sorunun ortaya çıktı̆̆ bildirilmektedir (15). 2003 yılında SARS salgınında SARS ile ilgili bölümlerde çalışan sağlık personellerinde stres bozukluğu düzeyi normalden 2-3 kat daha yüksek olduğu bulunmuştur (16).

Salgın döneminde meydana gelen değişiklikler paramedik öğrencilerinin duygu durumlarını etkilediği görülmektedir. Yapılan bir çalışmada COVID-19 olan bireylerin bulaştırma riskini önlemek için karantina uygulanması, kişilerde damgalanmışlık hissi, depresyon ve uyku problemlerine sebep olduğu bildirilmiştir (17). Brooks ve arkadaşları tarafından yapılan bir çalışmada ise, sosyal izolasyon döneminde hapsedilme hissi, olağan rutinin kaybı ve başkalarıyla sosyal ve fiziksel temasın azalmasının sıkıntıya, hayal kırıklığına ve diğerlerinden soyutlanma hissine neden olduğunu göstermiştir (18). Ruhsal durumdaki bu değişikler nedeniyle iş doyumunda azalma, görev ve sorumlulukları eksiksiz olarak yerine getirememe gibi çalışama hayatında olumsuzluklara neden olabilir.

Çalışmaya katılan bireylerin salgın döneminde de mesleğini yapmak istediği, paramedik olarak çalıştığında COVID-19 salgınının işine olan bağımlılığını düşürmeyeceği ve çevresindeki kişilere paramedik mesleğini tavsiye edeceği görülmektedir. 2003 yılında ki SARS salgınında sağlık çalışanlarına yönelik yapılan çalışmada bizim çalışmamızdan farklı olarak sağlık çalışanları salgın döneminde hastanede ve hasta bireylerle oldukları için bir kısmının damgalanma hissettiklerini bu yüzden mesleğe bakış açılarının değiştiğini, mesleğe olan bağlılıklarının azaldığını ve istifa etmeyi düşündüklerini ifade etmiştir (19). Öğrencilerin sahada çalışan sağlık personellerine göre düşüncelerinin farklı olmasının sebebi; sahada aktif olarak COVID-19 hastaları ile çalışmadığı, mesleğe bakış açılarının olumlu ve motivasyonlarının yüksek olduğu için bu sonuçlar elde edildiği düşünülmektedir.

Sonuç olarak; COVID-19 salgını sonrası paramedik öğrencilerinin mesleğe bakış açılarını belirlemek amacıyla yapılan bu çalışmada; öğrencilerin salgın döneminde paramedik mesleğine bakış açılarının etkilendiği, salgın süresince paramedik mesleğini yapmak istedikleri, çevresindeki insanlara paramedik mesleğini tavsiye edecekleri ve çalışrken COVID-19 hastasına gerekli uygulamaları eksiksiz yerine getirecekleri sonucuna varılmıştır.

Çalışma sonuçları doğrultusunda şu önerilerde bulunulmuştur;

Öğrencilerin COVID-19'a karşı almış olduğu tutum eğitim seviyesi ile ilişkili olduğu için okul döneminde öğrencilere bulaşıcı hastalıklar, salgınlar hakkında detaylı eğitime yer verilmelidir. Gelecekte sahada çalışacak olan öğrencilerin mesleki performanslarının düşmemesi için salgına yönelik tedbirler en üst düzeyde alınmalıdır. Öğrencilerin mesleğe başlamadan COVID-19 salgınına ve tüm bulaşıcı hastalıklara yönelik hastaya yapılan uygulamalarda bulaşıcılık faktörü için detaylı eğitim programı planlaması önerilmektedir.

\section{Teşekkürler}

Çalışmamıza katılarak destek veren tüm öğrencilere teşekkür ederiz. Araştırmanın veri toplama aşamasında emeği geçen KSÜ Göksun SHMYO İlk ve Acil Yardım Programı hocalarına ve öğrencilerine katkılarından dolayı teşekkür ederiz.

\section{Çıkar Çatışması Beyanı}

Yazarlar arasında herhangi bir çıkar çatışması yaşanmamışıtır.

\section{Araştırma Desteği}

Çalışmayı maddi olarak destekleyen kişi/kuruluş yoktur.

\section{Beyanlar}

$\mathrm{Bu}$ çalışma herhangi bir yerde sunulmamıştır.

\section{KAYNAKLAR}

1. Gençalp DK. COVID - 19 salgını döneminde ilk ve acil yardım öğrencilerinin beslenme alışkanlıkları ve fiziksel aktivite durumlarının değerlendirilmesi. Paramedik ve Acil Sağllk Hizmetleri Dergisi. 2020; 1(1): 1-15.

2. Gündüz T, Arserim SK, Lİimoncu ME, Balcı Ö. İlk ve acil yardım teknikerliğinde eğitimin değerlendirilmesi. Hastane Öncesi Dergisi. 2018;3(2):121-9.

3. Göllüce A, Avan H, Karsu F. Öğrenci gözüyle paramedik mesleği. Hastane Öncesi Dergisi. 2017;2(1):1-9. 
4. Demirağ H, Hintistan S. İlk ve acil yardım programı öğrencilerinin yaz stajı hakkındaki görüşlerinin incelenmesi. Ordu Üniversitesi Hemşirelik Çalışmaları Dergisi. 2019; (1): 46-55.

5. Chang L, Yan Y, Wang L. Coronavirus Disease 2019: Coronaviruses and Blood Safety. Transfus Med Rev. 2020; 34(2): 75-80.

6. Liu S, Yang L, Zhang C, Xiang YT, Liu Z, Hu S, et al. Online mental health services in China during the COVID-19 outbreak. The Lancet Psychiatry. 2020; 7(4): 17-18.

7. Adams JG, Walls RM. Supporting the Health Care Workforce during the COVID-19 Global Epidemic. JAMA - J Am Med Assoc. 2020; 323(15): 1439-1440.

8. Duan L, Zhu G. Psychological interventions for people affected by the COVID-19 epidemic. The Lancet Psychiatry. 2020; 7(4): 300-302.

9. Ergün E, Ergün Ş, Çelebİ İ. Acil sağl1k hizmetleri personellerinin Covid - 19 hakkında bilgi, korunma düzeyleri ve etkileyen etmenler. Paramedik ve Acil Sağlık Hizmetleri Dergisi. 2020; 1(1): 16-27.

10. Sayed M El, Kue R, McNeil C, Dyer KS. A descriptive analysis of occupational health exposures in an urban emergency medical services system: 20072009. Prehospital Emerg Care. 2011; 15(4): 506-510.

11. Kim OS, Oh JH, Lee kyung $\mathrm{H}$. The convergence study on anxiety, knowledge, infection possibility, preventive possibility and preventive behavior level of MERS in nursing students. J Korea Converg Soc. 2016; 7(3): 59-69.
12. Perkins A, Kelly S, Dumbleton H, Whitfield S. Pandemic pupils: COVID-19 and the impact on student paramedics. Australas J Paramed. 2020; 17: 1-4.

13. Soysal F, İşler SÇ, Peker İ, Akca G, Özmeriç N, Ünsal B. COVID-19 Pandemisinin Diş Hekimliği Uygulamalarına Etkisi. Klimik Dergisi. 2020; 33(1): 5-14.

14. Cetintepe SP, İlhan MN. COVİD-19 salgınında sağlık çalışanlarında risk azaltılması. J Biotechnol Strateg Heal Res. 2020; 1(Özel Say1): 50-54

15. Baltacı NN, Çoşar B. COVID-19 pandemisi ve ruh beden ilişkisi. Türkiye Klin. 2020; 1(Özel sayı): 1-6.

16. Wu P, Fang Y, Guan Z, Fan B, Kong J, Yao Z, Liu X, Fuller CJ, Susser E, Lu J, Hoven CW. The psychological impact of the SARS epidemic on hospital employees in China: Exposure, risk perception, and altruistic acceptance of risk. Can J Psychiatry. 2009; 54(5): 302-11.

17. Röhr S, Müller F, Jung F, Apfelbacher C, Seidler A, RiedelHeller SG. Psychosocial Impact of Quarantine Measures During Serious Coronavirus Outbreaks: A Rapid Review. Psychiat Prax. 2020; 47: 179-89.

18. Brooks SK, Webster RK, Smith LE, Woodland L, Wessely S, Greenberg N, Rubin GC. The psychological impact of quarantine and how to reduce it: rapid review of the evidence. Lancet. 2020; 395(10227): 912-20.

19. Chong MY, Wang WC, Hsieh WC, Lee CY, Chiu NM, Yeh WC, Huang TL, Wen JK, Chen CL. Psychological impact of severe acute respiratory syndrome on health workers in a tertiary hospital. Br J Psychiatry. 2004; 185: 127-133. 